3. That bacteriologists have hitherto almost entirely neglected the question of the relative abundance of micro-organisms of different sort in pure and impare substances-for example, water as compared with sewage, virgin soils as compared with polluted and cultivated soils, etc.

4. That attention to this question of relative abundance has a most important bearing on the bacterioscopic analysis of potable waters from the public health point of view, because it shows that the biological distinction between pure and impure substances (for example, water and sewage) is so great as to be almost inconceivable, so great as to render the adoption of rigid and stringent bacteriological standards unnecessary and inadvisable, and so great, also, as to allow the bacteriologist to detect in a water the presence of objectionable polluting material in quantity so small as to be far beyond the reach of chemical analysis.

5. That streptococci are absent from ro c.cm. (or more); B. coli from I, 10, it may be 100 c.cm. (or more); and B. enteritidis sporogenes from 100 to $500 \mathrm{c.cm}$. (or more) of pure waters; that is, these microbes are altogether absent or relatively so from pure waters.

6. That streptococci, B. coli, and B. enteritidis sporogenes are commonly present in $1 \frac{1}{10} \mathrm{c.cm}$., to ro' c.cm. respectively of crude sewage; that is, these microbes are present in crude sewage in great abundance.

7. That it is evident from these figures that there are tests available to the bacteriologist in the bacterioscopic examination of potable waters which far surpass in delicacy any known chemical tests.

8. That a stage may be reached in the pollution of water with sewage when the contaminating material is so small in relation to the bulk of water as to be inappreciable by chemical means, while yet yielding to bacteriological tests unequivocal evidence of gross pollution with microbes of intestinal origin. This is a matter which has passed the stage of controversy

9. That the presence of streptococci are to be thought of as indicating extremely recent. and $B$. coli less recent, but still not remote, pollution of animal sort, but that the presence of B. enteritidis sporogenes cannot be considered to afford evidence of pollution bearing a necessary relation to the recent evacuations of animals.

10. That streptococci and B. coli are either altogether absent or present in sparse amount in virgin soils, and may be absent even from polluted soils, unless the contamination is of comparatively recent sort. In soils recently polluted with animal matters streptococci and B. coli are of course present in abundance. B. enteritidis sporogenes may be present even in seemingly virgin soils, but in sparse proportion compared with the large number found in cultivated and polluted soils. ${ }^{8}$

I1. That the presence of streptococci in any number in a water supply points not only to recent animal pollution, but also implies that the antecedent conditions - conditions intervening between the period of pollution of the water and the time of collection of the sample-could hardly have been of so unfavourable a character as to destroy the vitality of seemingly more hardy microbes-for example, the typhoid bacillus. Quite the same cannot be said for the $B$. coli test, since $\mathrm{B}$. coli is a more hardy germ than $\mathrm{B}$. typhosus.

12. That organic matter per se is, so far as we know, harmless, it is the bacteria apt to be associated with the organic matter that constitutes the element of danger.

13. That the amount of organic matter in a drop ${ }^{9}$ or even a few drops of sewage is so small as to be hardly appreciable on chemical analysis, and yet a like quantity of sewage can be shown by bacteriological tests to harbour objectionable germs in great abundance.

14. That it is not necessary to demonstrate in a polluted water supply the presence of definitely pathogenic microbes to prove that there is danger in drinking such water.

15. That it is sufficient to show that microbes indubitably of intestinal origin are present in a water to condemn that water, because it is beyond controversy that these microorganisms are apt at any time to be accompanied by other bacteria which are clearly known to cause disease in human beings.

16. That the bacteriologist can show that between a pure water and a water contaminated even with minute traces of excremental matter there exists a biological difference not only of degree but of kind.

17. That under like conditions the chemist may fail to appreciate the pollution altogether, and most certainly can form no conception of its dangerous character.

18. That the chemist's methods of endeavouring to ascertain the truth in the analysis of water are necessarily indirect ones, and all his standards of potability are based on an assumed relationship which may or may not exist between the amount of organic matter and the number and character of the associated bacteria.

19. That valuable as the chemical analysis of a water uno oubtedly is, it ought in the future to occupy a secondary position, and the bacteriological examination take its place in judging the purity or otherwise of our water supplies.

20. That until these facts are recognised and acted upon progress in the prevention of waterborne disease must needs remain unsatisfactory. ${ }^{10}$

\section{NOTES AND REFERENCES.}

1 Reports to the Local Government Board. 2 Much credit in this connection belongs to Dr. M. H. Gordon, Jvernal of Pathology and Bacteriolngy 8897. He stuaied over roo microbes isolated from stools, urine. sew ige, milk and water, all resenbling $B$. coli morphologically, and in gelatine and agar cultivations. These apparently similar microbes were found to differ in many cases in their attributes. and to be capable of heing classified as sixteen separate varieties. Many have since conflimed his results, but a few have failed to do so. The latter. I think, liave used some method or medium which either, destroys the majority of coll microbes present or tends to "draw out" a particular strain of B. coli at the expense of all other accompanying and possibly more important organisms of the coli tribe. 3 See reports by Dr. Kleln, Reports of the Medical Officer, Local Government Board, 1896-7-8-9; also reports by Dr. Andrewes, Report of the Medical Officer, Local Government Board, 1896-97, and Lancel, January 7 th, 1899. 4 heports to the Local Gornen Although it is of interest to fid that $\mathrm{B}$. enterists sporogenes may be present in substances bearing no conceivable relation to waters supply this fact cannot reasonably be adduced as an argument against the use Klein's test in the bacterioscopic examination of potable waters. Reports on the bacteriological examination of soll and water Report the Medical Officer Local Government Board, 1807-8-9-1900. TIn the ser se of being specially abundant in, or almost peculiar to, sewage. so in out of place. It may again be pointed out that the demonstration of B. enteritidis sporogenes in substances bearing no concelvable relating be water supply may be of interest. But why this circumstance. should be adduced as an argument against the employment of potable waters is not verz clear. $9 \mathrm{~A}$ single drop of the urine of a patient suffering from hot cleariluria may contain a million or more typhoid bacilli (Dr. ty Horth-sm 10 Since this paper was written Dr. Horrocks's treat lse on the 500,000.000). 10 Since this paper water has been published: the author finly confrms my contention that the presence of streptococei - Indicates sewage contamination, but he does not consider the presence of streptococci proof of recent pollution.

\section{ON RUBELLA, SCARLATINA, AND "FOURTH DISEASE." *}

By P. WATSON WILLIAMS, M.D.Lond., Physician to Clifton College and Bristol Royal Infimary.

IT is a matter of considerable importance that the existence of an infectious eruptive disease, having points of resemblanee to rubeola, rubella, and scarlatina, yet a distinct pathological entity, which has been so ably advocated by Dr. Clement Dukes ${ }^{i}$ under the term "fourth disease," should be recognised or refuted. It is needless to urge that rubella ${ }^{2}$ manifests variations from its normal symptoms and course ; inteed, it has been well described as "a disease specially got up to plague the young practitioner,"3 but often enough it puzzles the most experienced. Perhaps no one feels the need for help in the early accurate diagnosis of the exanthemata more than medical officers to schools, for while on the one hand it is of the utmost importance that scarlatina should be recognised and promptly isolated, it is, on the other hand, a disaster for a school to be credited with an outbreak of scarlatina, when in reality the disease is nothing more seriuus than German measles or perhaps " fourth disease."

The eminent position and long experience of Dr. Clement Dukes rightly stamps his differentiation of "fourth diseuse" with authority, and thus on all hands one hears of the rntbreak of epidemics which are diagnosed as this affection : To prove that such a disease does not exist requires a wider

* Read before the Bath and Bristol Bran 
experience than I can claim, but two recent epidemics occurring in Bristol seem to show that the symptoms of so-called "fourth disease" may be exactly simulated by both rubella and scarlatina, and thus Dr. Dukes's points of differential diagnosis of "fourth disease" become in practice almost valueless.

In brief, the question is: Are there two types of rubella? namely, rubella morbillosa and rubella scarlatinosa, or are these two types in reality two distinct diseases, the one not protecting from the infection of the other? A further question arises. Does scarlatina exhibit departures from its normal course, so as to present a group of symptoms indistinguishable from Dukes's "fourth disease."

In the course of an epidemic of rubella at Clifton 32 cases occurred in a school under my charge as physician. I was first asked to see a small boy in House $H$., who had been playing cricket and was said to have " heat spots." He was feeling quite well, but he had widely scattered small papules all over the body. The temperature was $99^{\circ} \mathrm{F}$. The following morning the rash had disappeared, the temperature was normal, and the boy well. Thirteen days later another boy in the house developed a similar rash, and I suspected the case to be very mild German measles, though there was no rise of temperature when I saw him. Four days later another case occurred with diffuse fine papular rash, but no temperature. He was the son of a medical practitioner, and when his father saw him he suggested it was like " fourth disease," of which he had just had several cases. The fourth case arising in the house was obviously rubella of " measles" type.

The same day another exactly similar case occurred in another house, M., of the junic.r school, and this one was followed by 18 more cases, only 4 in the house escaping. Many of these 18 cases were exceedingly mild, resembling the first case; others were the usual typical rubella of the measles type and one of the scarlatina type. Of the other cases 2 occurred in another junior house and the rest in senior houses in one house 2 cases, and $x$ case in each of four senior school houses.

It would serve no useful purpose to recount these cases in detail ; 3 cases alone call for special comment. The highest temperature in the majority of cases did not exceed $100^{\circ} \mathrm{F}$., and in none did it reach $102^{\circ} \mathrm{F}$. There was the usual enlargement of the posterior cervical glands in many, of the inguinal and axillary glands in a few, and mealy desquamation of the face and neck was observed in a large proportion.

The three cases I must allude to especially are:

CASE A.-No. 23 P. (No previous history of rubella or scarlatina.)

June 3 oth. Acute tonsillitis, very red fauces, vomited. Temperature 103. ${ }^{\circ} \mathrm{F}$.

July rst. Tonsillitis pronounced

July ond 2 . chest trunk and back, aleared, very profuse all over arms and wrists, somewhat punctate and fintly papula. somewhat punctate and finely papular, picking out hair follicle and shoulders. The fauces and palate brick-red es, especially over thigh cherry-red, and same colour on mucosa of lips. Themperature too ${ }^{\circ} \mathrm{F}$.

July 3 rd. Fauces and lips and tongue very red, marked tonsillitis, no submaxillary bubo. Slight enlargement of post-cervical glands, but no tenderness Rash all over body, but fading from feet and neck. Feels and looks much better. Temperature normal in morning, roo. $6^{\circ}$ evening. July 4 th. Feels fairly well. Faucial redness much less. Rash rapidly fading. Definite desquamation around lips, alæ of nose, and on forehead. July 6th. Desquamation of fingers, face powdery desquamation.

July $;$ th. Feet beginning to peel. Mixing freely with other boys from to-day.

July gth. Large flakes coming from soles and palms, as much as 4 square inches in size.

July 18 th. Feet, hands, wrists desquamating freely still, but abdomen finished.

July 22nd. Forearms only peeling now.

From July 7 th - that is, five days from appearance of rash-allowed to mix with other nine boys, none of whom contracted any fresh illness.

CASE B.-No. 25 E. (No previous history of rubella or scarlatina.) June 29th. Prodromal headache.

June 3 oth. Sore throat, no vomiting.

July rst.-Bright brick-red tonsillitis.
July 2 . Bd. Sore throat better: but profuse, red, punctate, fine papular rash all over chest, trunk, neck, not on the face. Temperature, evening, $99.6^{\circ}$.

Juiy zrd. Rash still profuse and scarlatiniform all over the body, but to-day appearing on the arms. Posterior cervical and inguinal glands enlarged and tender. Feels fairly well. Tongue coated, not red. Temperature, morning, $98.6^{\circ} ;$ evening, $100.6^{\circ} \mathrm{F}$

July 4 th. Face, neck, and chest powdery. The tongue and mucous membrane of the lips bright cherry-red. Later there was powdery desquamation of the skin of the abdomen.

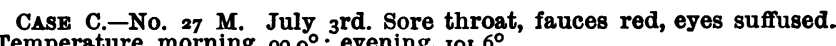
Temperature, morning, $99.0^{\circ}$; evening, ror. $6^{\circ}$.

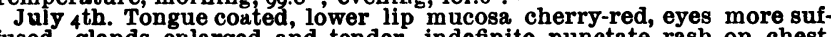
Temperature, morning, $98.6^{\circ}$; evening. $99.8^{\circ}$.

emperature, morning, $98.6^{\circ}$; evening. $99.8^{\circ}$. July 5 th. Tongue and mucous membrane of lips bright cherry-red. The usual morbilliform papular rash on chest trunk. Later des

(This case was of the morbilliform type, yet developed the cherry-red tongue, and peeled.)

In no case was there ever a trace of albuminuria, and in none were Koplik's spots observed-symptoms which were carefully and repeatedly sought for. The three cases A. B. and C., were all from different houses.

Now Case A could scarcely have been distinguished from scarlatina, indeed, despite the occurrence of the case in the midst of this epidemic of rubella, I could not at the outset say with any certainty that it was not scarlatina, and Dr. Harrison, who saw the case in consultation with me, could only go so far as to say he thought, like myself, that it was not scarlatina. The initial sore throat and vomiting, the high temperature, and profuse scarlatina-like rash, followed by very free desquamation, pointed to the graver disease, but the absence of albumen and of any pronounced malaise seemed to negative scarlatina. To all appearances it was, I venture to think, a very typical example of Dukes's "fourth disease," with this sole exception, that the tongue was bright cherry-red on the fourth day of illness. Case $B$ resembled Case $A$ in many respects, but was a less pronounced illness-sore throat with acute tonsillitis for two days, but becoming much relieved on the third day, when a profuse scarlatina-like red punctate papular rash appeared, the temperature being then under $100^{\circ} \mathrm{F}$.; mealy desquamation followed. This, again, was to all appearances a typical example of "fourth disease" except that the tongue and lips became bright cherry-red on the fifth day.

The first of these two cases after the fifth day of rash was allowed to mix freely with other boys who had rubella, and the second case was at no time separated from the rubella cases. Yet no boy contracted either scarlatina or " fourth disease" from them, neither did either of these two boys contract rubella from their constant companions. There is little room for doubt that all the 32 cases were suffering from German measles, and we see examples of every grade and variety of this exanthem from the mildest form which might readily pass for roseola æstiva to the more pronounced morbilliform and scarlatiniform varieties.

In an outbreak of rubella at Clifton College in 189I, recorded by my predecessor, Dr. W. J. Fyffe, ${ }^{5}$ there were 91 cases in all, and amongst them were 8 cases in which the usual pink papular discrete spots appeared and faded in due course, only to be followed after an interval of one to three or four days by a bright scarlet finely punctiform rash which covered the whole body, together with, in some cases, a fresh rise in temperature, sore throat and vomiting. There were also 5 other cases of this scarlatiniform rash without a primary papular rash, several of the 13 cases desquamating very freely. There was no evidence of any boy contracting this scarlatina-like rash from the various cases of rubella mixing together at the sanatorium. Dr. Haig Brown ${ }^{b}$ has also recorded 13 similar cases occurring at Charterhouse School in 1884 in the course of an epidemic of rubella. Five of these had previously had scarlatina, and in 1886 , when an epidemic of 202 cases occurred, not one of the 9 remaining in the school (out of the 13) contracted rubella.

There is undoubtedly a tendency for rubella to breed true as regards type, so that in any given epidemic the cases mostly exhibit either the morbilliform or the scarlatiniform type, but the occurrence of the two types together leaves no room for doubt that such two types of one and the same disease do exist.?

I will now turn to another group of 'cases of scarlatina resembling rubella, all arising from drinking milk from one supply, which has caused a recent epidemic in Clifton. Fresh from the careful observation of these 32 cases of rubella, I hoped I had so enlarged my experience that I should have little difficulty in differentiating this affection from developed scarlatina.

On August 3ist I was asked to see the following cases in one house.

CAsE 1.-W., aged ro, had a sore throat, and vomited two days before. A bright scarlatinal rash all over chest, trunk, legs, appeared this morning. 
The fauces bright-red, throat sore, tongue coated. Posterior cervical glands on either side enlarged. But the temperature was only ror. $2^{\circ}$, pulse roo. He appeared fairly comfortable, certainly did not feel very

I then saw three of the other children who were with him :

CASE II.-A baby, aged $1 \frac{1}{2}$, vomited yesterday, did not seem ill, and to-day is running about quite well. No rash.

CASE III.-B.. a boy, aged 6, vomited this morning, throat red, no rash two post-cervical glands enlarged and tender. Temperature $100.2^{\circ}$

CASE IV.-D., a girl, aged 4, vomited day before yesterday. Yesterday poorly : to-day punctiform red rasll on face, chest, and stomach, and an erythematous rash on the inner side of the right thigh. Pulse 18 . Temrature ror. $2^{\circ}$

Could these really be cases of scarlatina? They looked more like rubella. But I would not commit myself to a diagnosis, till I saw them with my colleague who was to take charge of them, as I was leaving for a holiday. He being a physician of very large experience, I felt that we migh reasonably hope to come to a definite and satisfactory decision. Thus the next day, on September ist, I saw the children with my friend.

CABE I (W.).- The rash to-day is fading on chest and trunk, still bright red and diffuse on the legs, and to-day has appeared on the feet, where it is more papular, just as the rubella rash spreads down. Tongue cleaning, labial mucosa bright red, like the rubella cases, Nos. 22, 25, 27,
marked tonsillitis. No submaxillary bubo. No albumen. Temperature 99.2०. Pulse 88.

CASE II (Baby).-Yesterday was well; to-day a diffuse papular scarlet rash all over back only. Tonsils full; throat not red; tongue clean. Posterior cervical glands on either side enlarged and tender. Tem-

CASE III (B.). - No rash, even to-day. Some tonsillitis. Temperature 99.4 Pulse 94. Tongue normal.

CASB IV (D.) - The rash of yesterday on the chest and trunk is only a diffuse subcuticular mottling to-day; the rash still on the inner side of die thigh, but to-day it has appeared on the hands and feet as diffus

We felt that there could not longer be reasonable doubt none of the children were really ill; the absence of fever, only slight rise in temperature, the low pulse-rate, the enlarged posterior cervical glands in several cases, and the character of the rash in those who showed any, namely, a tendency to be discretely papular, spreading gradually down to the feet, and the absence of albumen in the urine, seemed to exclude the possibility of scarlatina; so we reassured the mother, and told her it was certainly German measles.

Subsequently the marked desquamation in three of the children, and the occurrence of typical mild scarlatina with strawberry tongue, etc., in another child, left my colleague in no doubt as to the disease being scarlatina, but in no case did the urine contain albumen.

Now I cannol doubt that believers in "fourth disease" would have diagnosed these cases as that complaint.

However, these children were undoubtedly victims of the milk epidemic of scarlatina. Five days after the infected milk was begun the first child vomited and became ill. Lest it be argued that the milk episode was a mere coincidence, I will mention two cases in another house arising whilst $I$ was away from home.

A. F. S., aged 50 , developed sore throat, temperature $102^{\circ}$, and a scarlatiniform rash on the chest. The temperature did not fall to normal ill the fourth day.

On September 16th, A. D. S., his son, aged 7 , developed sore throat, rash on chest and back, temperature 100\%, enlargement of posterior cervical glands; no vomiting, no suffusion of conjunctiva. September 17th. Face very red and puffy. September 18th. Rash still out all over race and body, temperature ror. $5^{\circ}$, pulse rir. These cases were diagnosed by my colleague (not the same as in the group of children) as German measles. I then saw these two cases for the first time, and considered that the rash in the son was absolutely typical of scarlatina; moreover, the father was desquamating on the toes, face, and chest. My colleague, disease", Hered to his diagnosis of either German measles or " fourth me" he said, "one typical severe case of scarlatina with usual complicame," he said, "one typical severe case of scarlatina with usual complicatwo patients desquamated freely and I will admit it is scarlatina." These two patients desquamated freely, and in each case the process was not plications, and in the urine of the son only did I detect a very slight comof albumen for a few days, but there was no "strawberry tongue" at any time.

Neither patient had had rubella or scarlatina before, and the son certainly answered in all respects to the description of "fourth disease." But they were likewise victims of the infected milk supply. Numerous cases of scarlatina were being notified in one district, and Dr. Davies, M.O.H., found all the infected houses had their milk from the same source, and many of the patients were removed to Novers and Ham Green fever hospitals. If further proof be needed that these mild cases were true searlatina, I may point out that several of the group were treated in the fever hospital wards with many other scarlatina cases. yet no one of them contracted scarlatina in the hospital, nor did they communicate " fourth disease" to the other scarlatina patients.

The main points which, according to Dr. Dukes, serve to distinguish the "fourth disease" from scarlatina are ite prolonged incubation (nine to twenty-one days); the usual absence of pre-eruptive vomiting; the low pulse rate, which seldom reaches 100 ; absence of desquamation of the tongue about the fourth day; absence of renal complications; shorter period of infectivity. I would point to the group of scarlatina cases that $I$ have cited as exhibiting all the features that Dr. Dukes relies on as indicative of "fourth disease." Is it not possible that some of the cases hitherto recorded as "fourth disease" were rubella and some scarlatina?

Rubella occurs in two types, the morbilliform and the scarlatiniform, and it is remarkable how one or the other type prevails in any single epidemic. But do we not see the same thing in regard to other infectious complaints? Take, for instance, the protean influenza. At one time the gastrointestinal type has prevailed, at another the scarlatina form. at another the pulmonary, and so on. Scarlatina likewise in various epidemics exhibits types, as in the recent milk epidemic, throughout which, as far as I can hear, the cases ran a mild, though generally a fair typical course, yet very different from that exhibited in other epidemics, in which the cases are designated as scarlatina maligna.

When it can be shown that an attack of "fourth disease" protects the patient from rubella and yet occurs in those who have previously had scarlatina, the evidence of its being a distinct exanthem will certainly be very convincing, but hitherto such evidence is lacking.

\section{NOTEB AND REFERENCES.}

1 Lancet, July 14th, rgco, p. 89.2 Syn., German measles, rötheln. 3 Strahan, Med. Ann., 1894, p. 291 . 4 For example, Weaver, Dublin Medica Journal. 1900, p. 416. ${ }^{5}$ Bristol Medico-Chirurgical Journal, 1892. vol. X. cis of pales of $\mathrm{my}$ cases of rubella which have not nanely, that the round, pink, slightly raised, discrete papules in size and appearance resembling a typhoid spot, were often ringed round by distinct white ring. I had a patient under my care at the Royal Infirmary with ty phoid fever, and was told that she had developed an extraordnary crop of typhoid spots in place of the few spots she had before on the abdomen. The existence of this leucodermic ring suggested to me that she might have rubella, developing during the course of the yphoid fever, and the copious rash appearing also on the arms and Jegs tor two days and then completely fading, left me in no doubt, although the rubella.

\section{POST-SCARLATINAL DIPHTHERIA AND RHINOR- RHEA AND OTORRHEA.}

BY EGERTON H. WILLIAMS, M.R.C.S.ENG., L.R.C.P.LOND., M.D.Brux., D.P.H.Camb.

Medical Superintendent, City Hospitals, Sheffield.

Children convalescing from scarlet fever, especially in hospital practice, are without doubt peculiarly susccptible to the invasion of the diphtheria bacillus; not only is the mucous membrane of the throat liable to become infected, but also that of the nose, and to a lesser degree the surfaces about the external auditory meatus excoriated by discharge from the ear. It is my intention to record a few facts relating to rhinorrhœa apart from that associated with the acute stage of the disease, and otorrhœa, in scarlet fever wards in one of the Metropolitan Asylum Board Convalescent Hospitals gained by careful investigation over a period of three months and a half, from October 8th, 1900, to January $15^{\text {th }}$ of this year. This period I may say at once is far too short to admit of any dogmatic conclusion, but is sufficient to urge the immediate isolation and bacteriological examination of all such cases, with the object by so doing of reducing the incidence of post-scarlatinal diphtheria of the ordinarily recognised type.

Although the mortality of post-scarlatinal diphtheria has enormously decreased since the introduction and use of antitoxin in 1895-namely, from 43.8 per cent. in 1892 to 14.2 per cent. in 1895 , and 2.5 per cent. in 1899 , the importance 